\title{
A MEMÓRIA DA DITADURA EM DOIS ROMANCES LATINO-AMERICANOS: A LOUCURA E A GLÓRIA
}

\section{[The Memory of the Dictatorship in Two Latin American Romances: Madness and Glory]}

\author{
Analice Sousa Gomes ${ }^{1}$ \\ Renata Rocha Ribeiro ${ }^{2}$
}

Resumo: O objetivo principal deste artigo é apresentar uma discussão acerca da constituição da memória e dos possíveis significados evocados pelos relatos e pelas lembranças dos narradores-personagens nos romances Bêbados e sonâmbulos (1996) de Bernardo Carvalho e Duas vezes junho (2005) de Martín Kohan. Nesta análise, a loucura e a falsa glória, respectivamente, de contextos de governos militares no Brasil e na Argentina apresentam-se como temas contrastantes e, ao mesmo tempo, convergentes no que tange aos efeitos resultantes da configuração estética da memória em ambas narrativas. Deste modo, serão utilizadas, dentre outras, as concepções de Henry Bergson (1999) e Beatriz Sarlo (2005) sobre memória; de Maria José Rezende (2001) e Luis Alberto Romero (2012) sobre a reflexão historiográfica e filosófica dos contextos de ditaduras militares no Brasil e na Argentina, a fim de observar como se dá a estética da memória nos romances propostos para análise.

Palavras-chave: Ditadura; Memória; Bêbados e sonâmbulos; Duas vezes junho.

\begin{abstract}
This article discusses the relationship between the constitution of memory and the possible meanings evoked by the stories and memories of the narrators-characters in the novels Bêbados e sonâmbulos (1996) by Bernardo Carvalho and Duas vezes junho (2005) by Martín Kohan. In this analysis, the madness and the false glory, respectively, of military government contexts in Brazil and Argentina are presented as contrasting themes and, at the same time, converging with respect to the effects resulting from the aesthetic configuration of memory in both narratives. In this way, the ideas of Henry Bergson (1999) and Beatriz Sarlo (2005) about memory will be used, among others; by Maria José Rezende (2001) and Luis Alberto Romero (2012) on the historiographical and philosophical reflection of the contexts of military dictatorships in Brazil and Argentina, in order to observe how the aesthetics of memory occurs in the novels proposed for analysis.
\end{abstract}

Keywords: Dictatorship; Memory; Bêbados e sonâmbulos; Duas vezes junho.

\footnotetext{
1 Doutoranda em Estudos literários pela Universidade Federal de Goiás. Docente no Curso de Letras da Universidade Estadual de Goiás - Campus Jussara. E-mail: analice-jussara@outlook.com

2 Professora associada da Universidade Federal de Goiás-UFG. E-mail: renatarribeiro@ufg.br
} 


\section{INTRODUÇÃO}

As estratégias de (re)construção da memória na literatura latino-americana contemporânea, como elemento estético, têm mostrado os diferentes recursos utilizados na representação do passado de países que viveram sob o domínio de governos ditatoriais ao longo do século XX. Em linhas gerais, é isso o que ocorre com os romances Bêbados e sonâmbulos, de 1996, do autor brasileiro Bernardo Carvalho e em Duas vezes junho, de 2002, do argentino Martín Kohan.

Martín Kohan e Bernardo Carvalho, em suas narrativas, exploram de forma significativa os recursos da memória para recuperar as identidades perdidas ou não compreendidas de suas personagens. Em Segundos fora (2005), por exemplo, Kohan destaca a memória documentada por relatos, guardados em uma redação de notícias de um jornal, como ponto de partida para uma investigação de um jornalista esportivo desejoso em reconhecer-se em seu passado. Já em e Ciências morais (2007), também de Kohan, as personagens têm seu presente determinado por um constante trabalho institucional de permanência da memória coletiva, reproduzindo no presente das personagens os mesmos traumas do passado histórico.

Nos romances Nove noites (2002) e O sol se põe em São Paulo (2007), de Bernardo Carvalho, dentre outras ocorrências, os rastros de memória de personagens secundárias arrastam os narradores-personagens para uma busca investigativa que os removem de si mesmos, na tentativa de descobrir a verdadeira identidade daqueles indivíduos de cujas memórias eles se apropriaram. Percebe-se, dessa forma, que embora apresentem configurações diferentes, o recurso da memória é intensamente explorado por estes autores em suas narrativas.

Nesse sentido, a presente análise objetiva evidenciar as diferenças e semelhanças estéticas do uso da memória nos romances Bêbados e sonâmbulos, de Bernardo Carvalho, e Duas vezes junho, de Martín Kohan, partindo da concepção de memória apresentada por Henri Bergson em Matéria e memória (1999). De acordo com o autor, no campo epistemológico a memória é o fenômeno responsável pela conexão e pela reelaboração do passado no presente. Em seus termos, a

memória, praticamente inseparável da percepção, intercala o passado no presente, condensa também, numa intuição única, momentos múltiplos da duração, e assim, por sua dupla operação, faz com que de fato percebamos a matéria em nós, enquanto de direito a percebemos nela. (BERGSON, 1999, p. 77)

A partir desse conceito, observa-se que a memória "tem por função primeira evocar todas as percepções passadas análogas a uma percepção presente, recordar-nos o que precedeu e o que seguiu" (BERGSON, 1999, p. 266) e, consequentemente, auxiliar na interpretação do presente e de como é possível dele fazer parte. Em outras palavras, nesta concepção a "nossa memória escolhe sucessivamente diversas imagens análogas que lança na direção da percepção nova” (BERGSON, 1999, p.116), funcionando como fios condutores de lembranças constituintes do indivíduo, para torná-lo parte da realidade percebida. 
Assim ocorre com as memórias de Guilherme, um ex-militar homossexual, em $B \hat{e}$ bados e sonâmbulos, e de um soldado argentino, de nome desconhecido, no romance Duas vezes junho, ambos narradores-personagens. As lembranças e as reflexões nascidas a partir delas trazem, de diferentes formas, relatos de trajetórias expostas pela memória dessas personagens, suas impressões e suas versões testemunhadas no período da ditadura militar no Brasil e na Argentina. Tais relatos sobre o passado vivenciado e narrado nestes romances representam, sobretudo, a busca pela compreensão do presente em que se localiza cada um desses narradores-personagens.

Guilherme, ao acessar suas memórias, narra a trajetória investigativa que ele inicia para encontrar pistas que o levem à reconstrução de sua identidade e de suas lembranças perdidas em consequência de um tumor no cérebro. A partir disso, o protagonista se vê envolvido em situações de difícil compreensão, mistérios sem respostas claras quanto ao seu passado e de outras personagens como, por exemplo, o repatriamento sanitário de um psiquiatra brasileiro desaparecido na década de 70, que após nove anos reaparece, louco, numa pequena cidade do Chile. No decorrer dessa narrativa, torna-se evidente que as memórias do protagonista e do psiquiatra louco não são tão claras, se não quase inexistentes, transtornadas pelo tempo e pela doença, e suas identidades mutantes os direcionam a uma perturbadora busca de si mesmos, conduzida por uma mescla de encontros e desencontros.

O jovem soldado argentino em Duas vezes junho conduz seu relato mediante uma mescla de percepções e de fatos históricos ocorridos no final da década de 1970, quando a ditadura militar governava a Argentina. As memórias dessa personagem são intercaladas entre os conselhos de seu pai - um patriota que vibra com a convocação do filho para servir no exército - e os horrores vistos por ele mesmo, quando ingressa no serviço militar. Dessa forma, o soldado avalia a situação presente do país, o sentimento que emana do contexto opressor e sua própria identidade como indivíduo, como parte de um poder violento e esvaziado de humanidade.

Ambos os relatos, constituídos por memórias e lembranças individuais, desembocam na representação de fatos coletivos, isto é, remontam cenas da ditadura militar no Brasil e na Argentina, de modo que a fragmentação e os recortes do narrado pelas personagens produzem importante efeito estético para a representação de memórias traumáticas. Busca-se, a partir disso, observar como se dá a estética da memória e do testemunho retomando algumas ideias sobre o conceito de memória: fios que ligam o passado e o presente (BERGSON, 1999; SARLO, 2005) para, sobretudo, observar como se dá o diálogo entre os temas e estilos nos dois romances apresentado neste estudo.

\section{DITADURAS NA AMÉRICA LATINA: A LOUCURA NO BRASIL E A FALSA GLÓRIA NA ARGENTINA}

A ditadura militar na América Latina, segundo Maria José Rezende em Ditadura Militar no Brasil: repressão e pretensão de legitimidade 1964-1984 (2001) esteve ancorada em diversos fatores políticos mundiais, entre eles a Guerra Fria, o apoio econômico dos Estados Unidos e a intensa campanha deste país para combater a suposta ameaça do domínio comunista nos país latino-americanos. 
No Brasil, Rezende (2001) aponta que a suspeita de um governo comunista, identificado nas ações do então presidente João Goulart, fizeram com que as Forças Armadas do Exército brasileiro aplicassem o golpe de Estado em abril de 1964. Segundo a autora, esse foi um poder legitimado por meio da violência e da repressão:

Aqueles que não aderiam ao regime militar eram considerados fora dos parâmetros democráticos, portanto, expostos a todos os males que isto acarretava. A repressão e a violência contra o movimento operário, a desestruturação dos sindicatos, a limitação da lei de greve, etc., eram garantidas pelos atos institucionais; os quais eram apresentados como uma exigência da democracia que a ditadura estaria criando. (REZENDE, 2001, p. 83)

Tais mecanismos objetivavam a concentração de um poder inquestionável, justificando a "implantação do terror por parte do Estado" (REZENDE, 2001, p. 90), em nome de uma suposta democracia, principalmente quando passa a vigorar os Atos institucionais nos quais "prevalecia o arbítrio e institucionalizava-se a repressão e a tortura" (REZENDE, 2001, p. 91).

No romance Bêbados e sonâmbulos (1996), o narrador-personagem, Guilherme, ao se embrenhar pela busca intensa dos vestígios de sua memória, perdida devido ao tumor no cérebro, adentra numa atmosfera perturbadora, reafirmada pelas referências à loucura que surgem logo no início da narrativa. Primeiramente, o tema da loucura representa uma esfera individual, pois ele recorda sua infância, relacionando fatos desta fase com o desejo de se tornar psiquiatra, alegando que, ao ser o médico, não correria o risco de ser "enfurnado a contragosto" (CARVALHO, 1996, p. 22) em um hospício, como demostra o trecho abaixo:

Durante toda minha infância, costumava passar, em ônibus entupidos de gente, quase virando nas curvas, na frente do Pinel, para ir ao dentista no Centro, e a imagem dos doentes em uniformes azuis me aterrorizava. Ficava enjoado. Tinhas engulhos. Uma vez cheguei a vomitar de verdade [...]. Os loucos estavam nas sacadas com os mesmos uniformes azuis. Eu mal conseguia caminhar olhando para eles. Vi que um deles também olhava fixo para mim. Comecei a vomitar logo depois de ele gritar o meu nome. Ouvi bem: Guilherme! [...]. Ninguém mais ouviu [...]. Optei pela psiquiatria mais por precaução. Teria a garantia de não ser enfurnado a contragosto ali dentro eu também. (CARVALHO, 1996, p. 22).

Como se observa acima, o narrador rememora seu primeiro contato pessoal com a loucura, cujas lembranças carregadas de tensões psicológicas e físicas, determinam, até mesmo, as escolhas feitas na fase adulta da personagem: cursar medicina e se tornar psiquiatra. No entanto, este tema transcende a esfera individual quando Guilherme relata que, ainda cursando medicina, tomara a decisão de procurar seu amor de infância, Jorge, um tenente da escola dos cadetes, que segundo o narrador-personagem, motiva-o a abandonar o curso de medicina para se tornar um militar: 
Quando o neurologista me falou do tumor [...] me disse que eu ia esquecer quem eu era, pensei no Jorge [...] larguei tudo, para o escândalo da família, [...] encontrei-o e me enfurnei naquele quartel, como aspirante, ao lado dele, sob as ordens dele, agora que ele já é tenente, numa época em que não podia passar pela cabeça de ninguém se tornar militar. (CARVALHO, 1996, p. 23).

A partir desse momento, Guilherme recebe uma designação para acompanhar o repatriamento sanitário de um psiquiatra louco, desaparecido havia nove anos e encontrado no sul do Chile. Na sinuosa narrativa construída pelas memórias de Guilherme entrelaçadas aos relatos do desaparecido, as lembranças pessoais do narrador se misturam com as tensões vivenciadas pelo "louco", "filho único de um magnata do papel" (CARVALHO, 1996, p. 97). O futuro psiquiatra louco se mudara de Nova York para o Brasil, em 1957, simpatizando-se pelas ideias de um jovem contrário ao domínio militar.

O narrador conta que os amigos do jovem americano o traíram. Ele fora denunciado por eles sob a justificativa de que "tinha enlouquecido" (CARVALHO, 1996, p. 102). Foi, assim, raptado, torturado e sofreu o terror exercido pela ditadura militar no Brasil que, como já citado, se legitimara por meio da violência e da opressão. Preso, "desaparecido há cinco anos nas mãos das autoridades brasileiras" (CARVALHO, 1996, p. 108) e totalmente alheio à profundidade das conjunturas com que havia simpatizado, assassina o torturador e assume a identidade dele: um psiquiatra brasileiro. Tudo isso é revelado em uma carta endereçada a sua esposa, que foge do Brasil após o desaparecimento do marido:

O erro deles foi tê-lo deixado a sós comigo. Era um garoto. Um iniciante. Talvez tivesse ainda algum princípio. Eu seria capaz de tudo. Estava encurralado. Eu sou mortal, eu disse para ele, e o matei. Matei o psiquiatra naquela mesma noite em que, se não matasse teria morrido. Tomei o lugar dele, fiz dele o meu corpo dilacerado e irreconhecível. Fugi para o fim do mundo. [...] E se agora caí na própria armadilha da minha loucura - porque não tenho mais dúvidas de que estou louco [...]. (CARVALHO, 1996, p. 111)

A loucura, como reflexo do tortuoso evento vivido pela personagem, representa em Bêbados e sonâmbulos (1996) a asfixiante atmosfera da ditadura militar no Brasil. Não uma loucura individual, particular, mas sim um sentimento coletivo, compartilhado por todos que pertenciam a aquela realidade, viveram ou testemunharam a opressão do regime. No romance, Guilherme rememora tais acontecimentos quando ouve no rádio a notícia de uma mulher que perambulava pelo sul do Chile à procura de seu marido. Sem sucesso na busca, ela se joga no rio, fato que é noticiado pois estavam "à procura de sua origem e identidade" (CARVALHO, 1996, p. 112), como conta o narrador:

Ouvindo a notícia, eu pensei: sou a única testemunha - e, sem entender bem para que poderia servir o meu depoimento (quanto menos falar dela, melhor, porque só vi as duas cenas; o resto é uma mistura do que imaginei e do que me contaram depois), desliguei o rádio e acelerei antes que o sinal fechasse. (CARVALHO, 1996, p. 112). 
As duas cenas testemunhadas pelo narrador referem-se aos seus encontros com Elena, esposa do preso político que matou o psiquiatra, assumiu sua identidade e desapareceu. Tais encontros ocorreram devido a um acidente de avião que Guilherme sofrera ainda na infância, juntamente com seus pais e irmão, no qual também estava Elena. Um fato totalmente obscuro para o narrador-personagem, percorrido por ele durante toda a narrativa em meio a outros acontecimentos, torna-se um trabalho incessante pela busca de fios da memória e de pistas que o ajudem a desvendar os motivos e as consequências de tal acidente, da morte do pai e do irmão.

A ditadura também é o contexto do romance Duas vezes em junho (2005), narrado sob a ótica de um militar argentino, o narrador-personagem não nomeado, que rememora suas impressões do testemunhado e das ordens executadas, em nome do Exército e do poder que dirigia seu país. Embora o enredo transcorra, do mesmo modo que em Bêbados e sonâmbulos (1996), no final da década de 1970, na Argentina o domínio militar percorre sucessivas tomadas de governo marcadas, principalmente, por instabilidades econômicas, políticas e sociais internas e externas.

Segundo Luis Alberto Romero em Breve historia contemporánea de la Argentina 19162010 (2012), a primeira tomada de poder no país ocorreu em setembro de 1930, episódio no qual Yrigoyen, o até então presidente, foi "depuesto por un alzamiento militar"3 (ROMERO, 2012, p. 52). Tal fato surge, de acordo com Romero (2012) como resultado de uma intensa insatisfação popular, reunindo sindicatos, organizações de fazendeiros, grupos pertencentes à União Popular Católica Argentina (UPCA), dentre outros, que exigiam a reconstrução do país. O povo vivia uma constante desconfiança quanto às "bondades de la democracia liberal e patricia"4 (ROMERO, 2012, p. 62) do governo de Hipólito Yrigoyen, o que contribuiu para o despertar do Exército quanto ao andamento "de los asuntos políticos, quizá molesto por la forma en que Yrigoyen lo empleaba para abrir o cerrar la válvula del control social" 5 (ROMERO, 2012, p. 62).

Nesse sentido, Romero (2012, p. 52) aponta que a partir de 1930, somente cinquenta e nove anos depois "un presidente electo transmitiera el mando a su sucesor". Em outras palavras, até a década de 1980 a Argentina foi dominada por governos militares através de sucessivos golpes, intensa violência, assassinatos e censura. Ao modo da maioria das ditaduras de outros países da América Latina, inclusive o Brasil, na Argentina tal regime se auto justificava com fortes promessas para resolver a crise social e trazer estabilidade econômica ao país. No entanto, Alejandro Horowicz, em seu estudo historiográfico intitulado: Las dictaduras Argentinas: historia de una frustración nacional (2013), apresenta, de forma sintetizada, as verdadeiras intenções das tomadas de poder, evidenciadas no decorrer da história argentina:

\footnotetext{
3 “deposto por uma revolta militar". (Tradução nossa).

4 "bondades da democracia liberal e patriótica". (Tradução nossa).

5 "dos assuntos políticos, talvez incomodados pela forma com que Yrigoyen o usava para abrir e fechar a válvula do controle social”. (Tradução nossa).
}

6 "Um presidente eleito transmitiria o mandato a seu sucessor". (Tradução nossa) 
El golpe del año treinta desalojó al gobierno constitucional de Hipólito Yrigoyen del poder, el de 1943 evitó la victoria electoral fraudulenta de Robustiano Patrón Costas, sin incluir solución parlamentaria directa. En 1955 derrocaron al gobierno constitucional del general Perón; tanto en 1962 como en 1966 el golpe tuvo un solo objeto: impedir el triunfo electoral del peronismo. Y el de 1976 se ejecutó bajo la pancarta de evitar el triunfo de la guerrilla revolucionaria. Dicho epigramáticamente: dos golpes se hicieron contra presidentes de legalidad perfecta (Yrigoyen y Perón), tres para evitar un resultado electoral (1943, 1962 y 1966), y uno para instalar una dictadura burguesa terrorista unificada, iniciando así un nuevo ciclo de la historia nacional de muy relativa estabilidad institucional, pero sin golpes de Estado. (HOROWICZ, 2013, p. 29).?

A perspectiva apresentada por Horowicz (2013), destacando a "frustração nacional", corresponde aos sentimentos alimentados pelos argentinos em cada tomada do poder pelos militares: propagados como meio único de reconstrução do país e culminando em crises de ordem social, econômica e ideológicas. Mais tarde, no golpe de 1976, a Argentina "había desatado una crisis económica que hasta el final resultó imposible de dominar [...] la crisis económica preparo la crisis política"8 (ROMERO, 2012, p. 292) juntamente com uma ameaça de ascensão comunista, quando em 24 de março as Forças armadas depuseram o governo da então presidente Isabel Perón, e "como en ocasiones anteriores, el grueso de la población recibió el golpe com inmenso alivio y muchas expectativas"9 (ROMERO, 2012, p. 293).

O modo como a população recebeu o golpe de 1976, considerado o mais violento e arbitrário da história argentina, é representado em Duas vezes junho (2005) por meio das memórias do narrador-personagem que recorda a expectativa da família quanto a sua convocação para ingressar no serviço militar, enxergando tal ingresso como uma honra, um sinal de patriotismo:

O rádio disse: "número de ordem". "Seiscentos e quarenta”.

Eu era o seiscentos e quarenta.

Meu pai disse que ele estava muito orgulhoso. E era verdade: tinha nos olhos um brilho como de lágrimas que não iam sair. (KOHAN, 2005, p. 12)

\footnotetext{
7 "O golpe dos anos trinta derrubou o governo constitucional de Hipólito Yrigoyen do poder, o de 1943 evitou a vitória eleitoral fraudulenta de Robustiano Patrón Costas, sem incluir solução parlamentar direta. Em 1955 derrubaram o governo constitucional do general Perón; tanto em 1962 como em 1966 o golpe teve um só objetivo: impedir o triunfo eleitoral do peronismo. E o de 1976 se executou sob a bandeira de evitar o triunfo da guerra revolucionária. Engenhosamente dito: dois golpes se fizeram contra presidentes de perfeita legalidade (Yrigoyen e Perón), três para evitar um resultado eleitoral (1943, 1962 e 1966), e um para instalar uma ditadura burguesa terrorista unificada, iniciando assim um novo ciclo da história nacional de uma muito relativa instabilidade institucional, mas sem golpes de Estado". (Tradução nossa).

8 "desencadeou uma crise econômica que até o final se mostrou impossível de dominar [...] a crise econômica preparou a crise política” (Tradução nossa).

9 "como em ocasiões anteriores, a maior parte da população recebeu o golpe com imenso alívio e muitas expectativas" (Tradução nossa).
} 
No serviço militar obrigatório, na Argentina, os cidadãos eram convocados a servir na "Força Aérea, na Marinha, ou no Exército [...] de acordo com os últimos três números do documento de identidade" (KOHAN, 2005, p. 12), como ocorreu com o protagonista do romance, sorteado, o jovem recruta enche seu pai de orgulho, pois servirá à reestruturação e ao progresso do país.

No entanto, a possível glória do serviço militar se desmistifica à medida que o recruta narra a violência, sem provas concretas e até mesmo gratuita, exercida sobre diferentes pessoas e circunstâncias. Entre as lembranças das sugestões que o pai lhe dava sobre o bom comportamento de um soldado, o narrador se recorda de um bilhete que trazia a seguinte mensagem: "A partir de que idade se pode comesar a torturar uma criança?" (KOHAN, 2005 , p. 11). Inicialmente ele perturba-se com o erro ortográfico da palavra "começar", que em vez de "ç", foi escrita com "s", mas logo as inquietações sobre o questionamento lido se transferem para a barbaridade do ato. O sargento Torres, seu superior, requer dele a resposta à pergunta do bilhete: "O que você acha, soldado?". Este hesita, mas em obediência responde: "A partir do momento em que a Pátria o requeira" (KOHAN, 2005, p. 21). Então confessa, na narrativa, que dera tal resposta somente para agradar ao sargento, conforme seu pai lhe havia indicado: "o superior sempre tem razão, ainda mais quando não a tem [...] no serviço militar, convém nunca saber de nada" (KOHAN, 2005, p. 15, 17).

A criança alvo da possível tortura havia nascido em uma sala, nas dependências do quartel, onde a mãe estava detida, suspeita de participar de um grupo de resistência aos militares. Grávida, a prisioneira sofria vários tipos de torturas: no "trato retal", "técnicas interrogativas de imersão", "aplicação de correntes elétricas", "golpes [...] dirigidos à zona abdominal”, "métodos de pressão psicológica" (KOHAN, 2005, p. 23-26), entre outros. Após intensas torturas, a mulher não pronunciara "nenhum dos nomes", e por isso, "disseram que iam finalmente fuzilá-la tinham se cansado de esperar que colaborasse" (KOHAN, 2005, p. 42). Aquilo era uma farsa com o intuito de abalá-la psicologicamente, pois "voltaram a interrogá-la [...], exigem-lhe os nomes, os nomes, os nomes" (KOHAN, 2005, p. 43).

O recém-nascido é retirado da mãe pelos militares, que cogitam torturá-lo. Contudo, o doutor Padilha, médico responsável pela autorização da ação, incerto, resolve consultar instâncias superiores. O bilhete escrito pelo cabo Leiva, que questionava sobre a idade para começar a torturar uma criança, teve de ser entregue ao capitão Mesiano. Assim, o narrador-personagem, sendo seu motorista oficial, precisa localizar e informar seu superior sobre a urgência da resposta requerida: "localizar o doutor Mesiano e fazer com que respondesse a inquietude do doutor Padilha se converteu para mim numa questão de orgulho pessoal" (KOHAN, 2005, p. 44), diz o narrador. A partir de então, este é o fio condutor da narrativa, entremeado a lembranças de outros episódios testemunhados e vivenciados pelo narrador, como por exemplo o estrupo coletivo de uma garota realizado por soldados, a agressão de uma mulher adúltera pelo seu marido (ajudado pelo amante) e a derrota da seleção argentina de futebol no campeonato mundial.

Nesse sentido, a glória das promessas de reconstrução do país, o orgulho dos convocados para o serviço militar e a esperança do povo se converteram em episódios de extrema violência, num país governado pela censura, pelo medo e pela opressão. Como assinala Sabrina Steinke em seu artigo "A ditadura e a transição para a democracia na Argentina 
recente: desparecimento de cidadãos e cidadania” (2001, p. 1), apesar da trajetória conflituosa no espaço político argentino de mais de 50 anos, este longo período de instabilidade e medo não deixara "marcas tão profundas em seus cidadãos" como aquele do processo de Reorganização Nacional imposto em março de 1976, que

acabou com o período democrático, e desta forma, impondo o poder do Estado por meio da força, feriu os direitos do homem e sua cidadania. Antes de desaparecer com pessoas, desapareceram seus direitos fundamentais. Perdeu-se o direito à vida, a liberdade de expressão, o direito de morrer com dignidade. (STEINKE, 2001, p.1)

Observa-se que os enredos de Bêbados e sonâmbulos (1996) e de Duas vezes junho (2005) apresentam o contexto da ditadura observado a partir de duas perspectivas que, embora diferentes, desencadeiam sentimentos semelhantes. No primeiro romance um ex-militar narra a loucura. No segundo, a convicção inicial, de outro ex-militar, termina em completo desânimo, como é evidenciado no final da narrativa onde o narrador-personagem reflete: "Ultimamente não consigo me lembrar de meus sonhos. Quando acordo, tudo se apaga” (KOHAN, 2005, p. 147), como se o vivido e o testemunhado fossem um sonho difícil de recordar.

\section{ESPIRAL, COLAGEM E DOBRAGEM: A ESTÉTICA DA MEMÓRIA}

A memória em ambas narrativas é o elemento que conduz o desenrolar do enredo, compartilhando com o leitor as imagens de um passado recente, rememoradas pelos narradores. Nesse processo de rememoração, é possível perceber que os narradores-personagens estão em tempos cronológicos diferentes: um pouco mais distanciado do passado em Bêbados e sonâmbulos (1996) do que em Duas vezes em junho (2005). As lembranças dos narradores situam-se em acontecimentos ocorridos nos contextos das ditaduras da década de 1970, isto é, no Brasil, no auge dos Atos Institucionais e, na Argentina, em um último governo militar marcado pela barbárie e pela arbitrariedade.

Ao término de cada romance é possível observar que ao invés de desvendar os questionamentos que motivam as ações dos narradores-personagens - para Guilherme, os motivos que explicariam a morte do pai e do irmão em um acidente de avião e, para o soldado argentino, com quantos anos é permitido torturar uma criança -, emaranham-se ideias desconexas apontando para lugar nenhum.

Tal efeito corresponde ao modo de utilização do recurso da memória como elemento estético nessas narrativas. Tomando como base a perspectiva de Bergson (1999) no tocante a função da memória de evocar percepções passadas para compreender o que se dá no presente, descritas mais acima, vê-se que os narradores-personagens, ao adentrarem em "lugar nenhum" de suas vidas do presente, percebem-se como sujeitos nulos, empurrados pelo sistema, e sem uma identidade própria buscam no passado fios que os conduzam aos desvendamento de sua condição atual, vidas resultantes de lacunas e lapsos que não lhes seriam possíveis compreender. 
Dessa forma, Guilherme prestes a perde sua memória por completo, continua sem resposta clara para seu anseio. Por fim sua história pessoal perde o destaque enfatizando-se o destino duvidoso do suposto psiquiatra louco e sua esposa, ele ouve as notícias, recorda-se da mulher, desliga o rádio e acelera (CARVALHO, 1996, p. 112), de outra forma, uma história que não apresenta desfecho. O soldado argentino inerte diante da banalidade com a qual os militares enxergavam a situação do país, deixa o serviço militar e desse "sonho", como ele mesmo categoriza, permanece em sua mente somente as lembranças de uma prostituta (KOHAN, 2005, p. 147) que conhecera na companhia de seu superior, capitão doutor Mesiano.

Essas memórias fragmentadas são lançadas nas duas narrativas de modo entrecortado e independente. No romance de Kohan, essa fragmentação, segundo Fernanda Clemilda Santos de Oliveira Dante em seu artigo: "Duas vezes junho, de Martín Kohan: uma análise estético-histórica" (2017, p. 5), "pode ser compreendida como um recurso utilizado para demonstrar o desenvolvimento da memória não linear do narrador". Perspectiva essa que dialoga com a concepção apresentada por Beatriz Sarlo, em Tempo passado: cultura da memória e guinada subjetiva (2007, p. 98), afirmando que "o aspecto fragmentário de toda memória é evidente", pois os relatos característicos da pós-memória são condicionados por esquecimentos e preenchimentos que se atualizam de acordo com as percepções requeridas pelo presente, havendo, desse modo, a conexão das lembranças pelo efeito da reelaboração do passado no presente (BERGSON, 1999).

O todo significativo da narrativa do ex-soldado argentino vai se constituindo por meio de fragmentos de variadas extensões e assuntos: a formação dos jogadores da seleção argentina: "Filol, Olguin, Galván, Passarela, Tarantiní, Ardiles [...]” (KOHAN, 2005, p. 36); a mulher que foi obrigada a limpar os restos de seu parto: "arrumaram um balde e um trapo, e lhe ordenaram que limpasse o que tinha feito [...], 'coloque a placenta no balde' (KOHAN, 2005, p. 19); as anedotas de seu pai: "meu pai era um homem que gostava muito de contar anedotas" (KOHAN, 2005, p. 16); o adultério e a violência consequente; o fingimento do corpo nu de uma prostituta (KOHAN, 2005, p. 76, 78); “a garota que vem de bicicleta” e é violentada por cinco soldados (KOHAN, 2005, p. 81-84), são testemunhos entrecortados e rememorados a conta-gotas pelo narrador-personagem, causando um efeito de colagem, de quebra-cabeça, com peças que vão se unindo e fazendo sentindo na totalidade dos relatos, representando os rastros mnemônicos que se materializam na totalidade das lembranças (BERND, 2013).

No caso de Bêbados e sonâmbulos (1996), Suzana Scramim em Literatura do presente (2007, p. 154), destaca que a estrutura desse romance sempre está de acordo com o procedimento de dobragem e desdobragem da trama, de forma espiral, reforçando a ausência de sentidos das coisas. Desse modo, Jefferson Agostini Mello em "Duplicidades e contradições em Bernardo Carvalho: o estético e o político; o universal e o particular" (2012), citando a análise do francês Fabrice Gabriel (1998) sobre esse romance, mostra, ainda que, como recurso estético, a narrativa foi elaborada,

como um quebra-cabeça e conduzida com uma virtuosidade suficientemente 
alucinada, não se consegue resumir a intriga; ela funciona tanto como suspense quanto como metáfora da ficção, que multiplica os efeitos de espelho e as mises en abyme, para significar, no fim das contas, o arbitrário poético de toda fábula (GABRIEL, 1998 apud MELLO, 2012, p. 139)

É possível observar, diante dos aspectos apresentados por Scramim e Mello que no romance Bêbados e sonâmbulos as propriedades estéticas da narrativa apontam para a transfiguração do pensamento e memórias incertas do narrador-personagem, já que o quebra-cabeça que constitui o romance figura o mesmo quebra-cabeça contido nas lembranças que guiam a trajetória investigativa do protagonista.

Por meio das ideias apresentadas percebe-se nas ondulações representadas através das memórias dos narradores-personagens, a constituição da configuração estética dos romances. Em Duas vezes junho (2005), os processos de colagem dos fragmentos; em Bêbados e sonâmbulos (1996) o recurso de mise en abyme e o desenrolar do enredo em efeitos de dobragem e desdobragem e, sobretudo, o efeito espiral que tais elementos provocam nas narrativas, caracterizam a estética da memória exploradas por Martín Kohan e Bernardo Carvalho nestes romances.

Ao utilizar a memória como recurso estético ambos autores evidenciam por meio dos narradores-personagens a necessidade de expor uma revisão reflexiva sobre o passado. As ondulações, as lembranças apresentadas em camadas e desordenadamente, isto é, a dobragem e a desdobragem dos acontecimentos, desencadeiam nas narrativas o efeito espiral, de modo que, tal recurso estético mostra a afetação de fatos do passado que ainda permanecem nos indivíduos. Os traumas do testemunhado e do vivido são dispostos em lembranças difíceis de rememorar e quando os personagens decidem fazê-lo no presente, embora pareçam banais, percebe-se ao longo dos romances, que figuram peças de um quebra-cabeça nos quais ainda se debruçam para unir e completar lacunas de um tempo de vazios e dores.

\section{CONSIDERAÇÕES FINAIS}

A análise proposta neste trabalho percorreu as concepções de memória apresentadas por Bergson (1999) e Sarlo (2005) com o intuito de observar a relação do passado com o presente, isto é, a mediação promovida pelos fios de lembranças passadas que se atualizam conforme são requeridas pela vivência do presente. A partir disso, observou-se que as personagens representadas, nos dois romances analisados, lidam com atmosferas distintas frente ao contexto de ditaduras em seus países, porém, ambos encaminham-se para uma semelhante aspiração: buscam no passado pistas que os ajude a compreender o presente de suas vidas nulas.

Assim, é possível constatar alguns pontos de aproximação entre a produção dos dois autores. As duas narrativas possuem narradores-personagens que, no presente, são ex-militares, as memórias tanto de Guilherme quanto as do soldado argentino não apresentam grande intervalo entre o acontecimento e a rememoração. Essas lembranças, por sua vez, são banais, sem importância para cada um dos narradores, que ao final seguem suas vidas: 
um acelera o carro, após o sinal de trânsito abrir e, o outro concentra em perceber se as lembranças que possui de uma prostituta são ilusórias ou de fato foram experiências reais. Além dessas semelhanças, em Bêbados e sonâmbulos e em Duas vezes junho as memórias da ditadura recuperadas pelos narradores-personagens, por meio de recursos estéticos e literários, parecem estar concentradas em expor as verdades das ações praticadas por governos totalitários e opressores determinantes do passado recente de seus respectivos países e que parecem ter sido apagadas da memória do povo.

A partir dessas ideias, é importante destacar que o recurso da memória utilizado pelos autores, os efeitos de dobragem e desdobragem, a fragmentação, o entrecortar de lembranças dispostas em espiral pelos narradores, auxiliam na representação do sentimento de nulidade de um presente resultante do passado carregado de traumas e vivências esvaziadas. Em outras palavras, a estética da memória em Bêbados e sonâmbulos (1996) e Duas vezes em junho (2005) constitui a reprodução do testemunhado, e das impressões que os narradores-personagens tiveram acerca da barbárie e do caos de uma realidade afetada pelas infundadas ações de governos ditatoriais no Brasil e na Argentina. Sentimentos estes que transcendem a esfera individual e desnudam a apatia coletiva de sociedades construídas sob a dor, o medo e a desesperança. 


\section{REFERÊNCIAS}

BERGSON, Henri. Matéria e memória: ensaio sobre a relação do corpo com o espírito. Trad. Paulo Neves. Martins Fontes. São Paulo, 1999.

BERND, Zilá. Por uma estética dos vestígios memoriais: releitura da literatura contemporânea das Américas a partir dos rastros. Belo Horizonte: Fino Traço, 2013.

CARVALHO, Bernardo. Os bêbados e os sonâmbulos. São Paulo: Companhia das Letras, 1996.

DANTE, Fernanda Clemilda S. de O. Duas vezes junho, de Martín Kohan: uma análise estéticohistórica. Scripta Alumni, p. 1-19, 2017.

HOROWICZ, Alejandro. Las dictaduras argentinas: historia de una frustración nacional. Buenos Aires : Edhasa, 2013.

KOHAN, Martín. Ciências morais. Trad. Eduardo Brandão. São Paulo: Companhia das Letras, 2008.

MELLO, Jefferson Agostini. Duplicidades e contradições em Bernardo Carvalho: o estético e o político; o universal e o particular. Revista Faac, v. 2, p. 131-144, 2012.

REZENDE, Maria José. A. Ditadura Militar no Brasil: repressão e pretensão de legitimidade1964-1984. Londrina: Editora UEL, 2001.

ROMERO, Luis Alberto. Breve Historia Contemporánea de la Argentina 1916-2010. 3 ed. Buenos Aires, 2012.

SARLO, Beatriz. Tempo passado: cultura da memória e guinada subjetiva. Trad. Rosa Freire D’Aguiar. São Paulo: Companhia das Letras; Belo Horizonte: UFMG, 2007.

SCRAMIM, Suzana. Literatura do presente: história e anacronismo dos textos. Chapecó: Argos, 2007.

STEINKE, Sabrina. A ditadura e a transição para a democracia na Argentina recente: desparecimento de cidadãos e cidadania. In: II Semana Procad PUC-GO/UnB, 2011, Goiânia. Anais II Semana Procad PUC-GO/UnB, 2011. 
